\title{
Sentence frame contexts and lexical decisions: Sentence-acceptability and word-relatedness effects
}

\author{
GLENN M. KLEIMAN \\ University of Toronto, Mississauga, Ontario L5L IC6, Canada
}

\begin{abstract}
Many studies have explored the effects of single-word contexts on visual word recognition, and several models have been proposed to account for the results obtained. However, relatively little is known about the effects of sentence contexts. In the experiment reported, the contexts consisted of sentences with the final word deleted, and subjects made word-nonword (lexical) decisions on target strings of letters. Norms were collected to determine the most common completion for each sentence frame. The experiment yielded three main findings: (1) Lexical decisions were fastest for words that were the most common completions; (2) among words not given as completions in the norming procedure, decisions were faster for words related to the most common completions than for words unrelated to the most common completions; (3) also among words that were not produced as completions, decisions were faster for words that formed acceptable completions than for words that did not. These relatedness and sentenceacceptability effects were independent, so that the relatedness effect held even when the target words formed anomalous sentence completions. In order to account for these results, a model combining two types of processes is required. In the model described, schematic knowledge (Rumelhart \& Ortony, 1977) operates upon a semantic network to activate particular nodes, and this activation spreads to related concepts as in the Collins and Loftus (1975) model.
\end{abstract}

It is well established that a linguistic context can facilitate the recognition of written words. This was first shown in studies in which brief tachistoscopic exposures of words were presented and recognition duration thresholds were measured (Morton, 1964; Pillsbury, 1897; Tulving \& Gold, 1963). More recently, the lexical decision task has been used to study many aspects of context facilitation. In this task, subjects decide whether or not strings of letters form words, and reaction times and error rates are measured. In many studies using this task, the context has consisted of an individual word presented either simultaneously with or just prior to the target word. In the prototype experiment (Meyer \& Schvaneveldt, 1971), subjects saw two simultaneously presented strings of letters (e.g., bread butter, wine plame, nart thief) and decided whether or not both strings formed words. The pairs in which both strings formed words were of two types: those in which the

The experiment reported is part of a doctoral dissertation submitted to the Stanford University Department of Psychology. I would like to thank Charles Clifton, Ellen Markman, and Edward E. Smith for their helpful suggestions on many aspects of this work, and Linda Baker, Mary Humphrey, Doug Medin, Andrew Ortony, and Ed Shoben for their comments on earlier drafts of this paper. This research was supported by Grant MH-19705 from the U.S. Public Health Service, Contract US-NIE-C-400-76-0116 from the National Institute of Education, and Grant HD 00244 from the National Institute of Child Health and Human Development and by the University of Toronto. Requests for reprints should be sent to the author at Department of Psychology, Erindale College, University of Toronto, Mississauga, Ontario L5L 1C6, Canada. words were associated (e.g., bread butter, nurse doctor) and those in which the words were unassociated (e.g., bread doctor, nurse butter). The result of interest is that the average reaction time to decide that both letter strings are words is less for the associated pairs than for the unassociated pairs. That is, an associated word context facilitates the lexical decision.

Many studies have used the lexical decision task to explore further the associated context effect. Schvaneveldt and Meyer (1973) found that facilitation occurs even when an unassociated word is introduced between the two associates (e.g., bread star butter). Antos (in press), Fischler and Goodman (1978), Neely (1977), and Meyer, Schvaneveldt, and Ruddy (Note 1) used a sequential presentation procedure to study the effects of varying the delay between context and target words. Antos (in press) and Neely (1977) explored whether the effect is due to conscious or automatic processes, as described by Posner and Snyder (1975a, 1975b). James (1975) and Shulman and Davison (1977) examined changes in context facilitation of lexical decisions as a result of using different types of nonwords. Other studies (Becker \& Killion, 1977; Meyer, Schvaneveldt, \& Ruddy, 1974) have shown that the magnitude of the context facilitation effect increases when the target words are visually degraded. It has also been demonstrated that the context facilitation effect holds for word pairs that are semantically related even when they are not associatively related (Fischler, 1977; Kleiman, Note 2). 
Three models found in the current literature offer accounts of facilitation from single-word contexts, the spreading activation model (Collins \& Loftus, 1975; Meyer et al., Note 1), the logogen model (Morton, 1969), and the verification model (Becker, 1976; Becker \& Killion, 1977). The differences among these models are not relevant to this paper, and so only the spreading activation model will be discussed. According to this model (as described by Collins \& Loftus, 1975), each concept in memory is represented by a concept node in a network. From each concept node, there are links to other nodes that designate the properties of the concept. These properties are themselves concepts. For example, the node representing the concept "apple" is linked to nodes representing the concepts "fruit," "food," "round," "red," and so on. The links have labels designating the types of relationships between concepts. The label on a link can itself be a concept, so any relationship can be represented. Each link has an associated strength or accessibility, designating how easily activation can traverse it.

According to this model, when context primes or activates a concept, activation spreads from that concept node along the links of the network, activating each node it reaches. The activation of a node by context makes that node easier to access, so less sensory information will be needed to access it. Activation is like a signal from a source that is attenuated as it travels outward. The amount of activation dissipated as it traverses a given link is proportional to the accessibility or strength of that link. The total amount of activation that spreads from one concept to another is also affected by the number of intermediate paths connecting the two nodes. For example, if the node for "vehicle" is activated, activation will spread directly to the nodes for "car," "truck," "bus," "ambulance," and so on. Some activation will then spread from each of these exemplars of vehicles to the others, so, for example, the total amount of activation reaching "truck" will be somewhat greater than the amount that traversed the direct link from "vehicle" to "truck." Therefore, the amount of activation that spreads from one node to another is a function of the number of paths between the nodes and the accessibility of the links in the paths. The value of this function reflects the relatedness of the two concepts. Context facilitation is predicted to occur whenever the concept named by the target word is highly related to the concept named by the context word.

Although the spreading activation model can account for the effects of single-word contexts, it does not provide an adequate account of facilitation from sentence frame contexts. (The same is true of the logogen and verification models.) With these contexts, both sentence comprehension processes and world knowledge come into play. For example, consider the following two sentence frames containing the same words in different orders: "The cup was placed on the __._.," and "Placed on the cup was the ." Sentence compre- hension processes must be used to differentiate the meanings of these two sentence frames, and world knowledge must be used to determine suitable completions; that is, what cups are usually placed on (tables, saucers) and what can be placed on cups (saucers, but not tables).

The focus of this paper is the effect of sentence frame contexts on lexical decisions. Three hypotheses will be considered: a specific facilitation hypothesis, an acceptable completion hypothesis, and a general facilitation hypothesis. These hypotheses are derived from three models of facilitation from sentence frame contexts, as described below. All three models assume that both sentence comprehension processes and world knowledge are involved in determining context facilitation.

According to the specific facilitation hypothesis, a sentence frame context will facilitate recognition only for those words that subjects generate when given the context as a prompt in a sentence completion task. This hypothesis can be derived from a model that incorporates the notion of schemata as representations of world knowledge (Rumelhart, 1977, in press; Rumelhart \& Ortony, 1977). Schemata are mental structures representing general concepts of objects, events, or situations. Each schema specifies the major elements of what it represents and the interrelations of these elements. The elements can be viewed as slots or variables. The process of comprehension involves retrieving appropriate schemata and filling the slots with specific instances. To take a simple example, a dinner schema might contain slots for appetizer, main dish, dessert, and so on, as well as slots for time and setting. Understanding a description of a dinner requires filling these slots with the appropriate particulars found in the description. One of the important characteristics of the slots is that each one has associated constraints that specify the types of elements that can fill it. For example, the constraints would specify that steak is a likely main dish, but lettuce is not. In addition, slots can have default values that are accessed when the input does not specify how the slot should be filled. For example, the default utensil for eating many foods might be a fork, rather than a spoon or a pair of chopsticks. ${ }^{1}$

Applied to context facilitation, the model claims that the sentence frame context enables the retrieval of a relevant schema. The context would usually contain sufficient information to fill some but not all of the slots. The default value for one or more of the unfilled slots would then be accessed. In the lexical decision and tachistoscopic recognition tasks, the default value is in some way primed, and this facilitates recognition. Since it is this default value that would be produced in a sentence completion task, this model predicts that facilitation will occur for the same words subjects produce as sentence completions.

According to the acceptable completion hypothesis, a sentence frame context will facilitate recognition for any word that forms an acceptable completion for that 
context. Therefore, this hypothesis predicts facilitation for all the words for which facilitation is predicted by the specific facilitation hypothesis, plus additional words that would not be generated in the production task but which form acceptable completions. A schema-based model could also yield this prediction, but rather than just the default value being primed, facilitation is predicted to occur for all words representing concepts that meet the constraints on the unfilled slot(s).

The third hypothesis, the general facilitation hypothesis, stems from the spreading activation model combined with some mechanism that determines completions for the sentence frames. According to this view, the context will activate the nodes representing words that best complete it. Activation will then spread from these best completions to closely linked nodes. Therefore, the maximal amount of facilitation should occur for words that best complete the context, but some facilitation should also occur for words that are highly related to these best completions. It is important to note that, according to this model, the facilitation of words related to the best completions is not affected by whether or not the related words form acceptable completions of the context.

In the experiment to be reported, which tests these three hypotheses, subjects determined whether strings of visually presented letters formed words, and reaction times and error rates were measured. Data were collected for each target word presented with and without a preceding sentence frame context, and the relationship of the target word and the context was varied. This procedure has been used in several recent studies (Fischler \& Bloom, 1979; Schuberth \& Eimas, 1977). In these studies, comparisons were made between reaction times for the same words without a preceding context (or in other control conditions). This was done in order to separate context facilitation effects from context interference effect. However, as discussed below, factors such as processing load and response readiness can differentially affect reaction times in context and control conditions, and therefore comparisons across these conditions are problematic. It cannot be assumed that faster reaction times in the context condition demonstrate context facilitation like that assumed in prior studies, nor that slower reaction times in the context condition demonstrate context interference.

Schuberth and Eimas (1977) showed some concern for the possible problems due to effects of processing load. They examined the effects of sentence frame contexts on three types of target strings: congruous words, incongruous words, and nonwords. They used two control conditions, a no-context condition and a spelled digit-string context condition (e.g., THREE SIX FIVE NINE). The intent of the digit context was to control for processing load, since it is possible that processing the sentence frame context would slow any response, even responses to nonlinguistic stimuli. When compared with the digit-string control condition, the results in the sentence frame context condition showed facilitation for all three types of targets, with the effect being largest for the nonwords, next largest for the congruent words, and smallest for the incongruent words. When compared with the no-context control condition, the results showed facilitation for nonwords and congruous words, but interference for incongruous words. Therefore, depending on which condition is taken as the proper control, sentence contexts either facilitate or interfere with recognition of the incongruous words, and the magnitude of the facilitation effect for the other targets changes. The digit context, as compared with the no-context condition, increased reaction times about $70 \mathrm{msec}$ for all target types.

The response readiness problem is seen most clearly in data recently reported by Stanovich and West (1979, Experiment 2). They used a pronunciation task, rather than the lexical decision task. Subjects pronounced words in three conditions: (1) preceded by a congruous context, (2) preceded by an incongruous context, and (3) with no context other than the word "the." The response-stimulus interval (RSI), or time from when the subject read the last word of the context to when the target word appeared, was either $150 \mathrm{msec}$ or $750 \mathrm{msec}$. There was also a normal vs. degraded presentation factor, but this did not interact with the other factors, and so the reaction times reported here have been averaged over presentation conditions. At the 750-msec RSI, responses in the incongruous context condition averaged $42 \mathrm{msec}$ more than in the no-context condition; at the $150-\mathrm{msec}$ RSI this difference was a nonsignificant $12 \mathrm{msec}$.

According to Stanovich and West (1979), these data show that an incongruous context interferes with word recognition at the longer RSI but not at the shorter RSI, and this interpretation neatly fits their view of interference being caused by a relatively slow-acting conscious processor, along the lines of Posner and Snyder's (1975a, 1975b) model. However, examination of their data calls this interpretation into question. If incongruous contexts interfere with the response when the RSI is $750 \mathrm{msec}$, but not when it is $150 \mathrm{msec}$, then reaction times in the incongruous context condition should be longer when the RSI is $750 \mathrm{msec}$ than when it is $150 \mathrm{msec}$. However, this difference (averaged over normal and degraded presentations) is $15 \mathrm{msec}$ in the wrong direction. The purported interference is actually due to the average reaction time in the no-context condition being $44 \mathrm{msec}$ faster when the RSI is $750 \mathrm{msec}$ than when it is $150 \mathrm{msec}$. That is, the longer delay speeds decision times in the no-context condition, rather than slowing times in the incongruous context condition. This is the case even though the same subjects and stimuli were used at both RSIs. These results may be due to $150 \mathrm{msec}$ being less than the optimal warning period in the no-context condition. The warning time would be functionally longer in the context condition, since subjects were given time to read the context.

Data reported by Kleiman (1977, Experiments 1 
and 2) provide further evidence that minor changes in procedure can differentially affect reaction times in context and no-context conditions and thereby lead to erroneous interpretations of facilitation or interference if comparisons are made between context and no-context conditions. Fischler and Bloom (1979, Experiment 2) attempted to remedy these problems by using a control condition in which there is a sentence frame context for each trial and the target words are all anomalous completions of their contexts. However, this remedy requires the questionable assumption that subjects process the context in the same way when all the target words are anomalous completions as when some target words are acceptable completions.

These problems in distinguishing facilitation and interference will not be solved here. However, no direct comparisons will be made between data from the context and no-context conditions. In the study to be reported, the no-context condition is used to show that the reaction times and error rates for the sets of target words are equivalent when there are no context effects. The data from the target-word sets in the context condition are then compared with each other (not with the data from the no-context conditions). Since the hypotheses to be tested are primarily concerned with which sets of words show context effects, it is not critical whether a given difference is due to facilitation of one set or interference of another, or a combination of facilitation and interference. For example, the data will not enable us to distinguish between facilitation of words that form acceptable sentence completions and interference of words that form unacceptable completions. The critical point is that, in either case, some process must distinguish acceptable from unacceptable completions and operate differently upon the two sets. In order to simplify exposition, differences between target word sets in the context condition will be discussed in terms of facilitation of the faster set. The reader should be aware that these effects may be due to interference of the slower set or to a combination of facilitation and interference effects.

\section{METHOD}

This experiment used the lexical decision task to determine whether facilitation from sentence frame contexts is limited to those words subjects generate to complete the sentence (the specific facilitation hypothesis), whether facilitation also occurs for other words that form acceptable completions of the sentence (the sentence acceptability hypothesis), and whether facilitation occurs for words that do not form acceptable completions but are related to the words subjects generate as sentence completions (the general facilitation hypothesis).

\section{Stimuli}

There were three sets of stimuli used to test the three hypotheses, with stimulus set being defined by the relationship of the target word to the sentence frame context. An example context is "He hit the nail with the _._.." Other sample stimuli are shown in Table 1 . One set of stimuli contained words that
Table 1

Sample Stimuli

\author{
The cup was placed on the \\ table (best completion $=\mathrm{BC}$ ) \\ chair (related to expected word $=\mathrm{R}$ )* \\ floor (unrelated to expected word $=U$ )* \\ The king of the beasts is the \\ lion $(\mathrm{BC})$ \\ roar $(\mathrm{R})^{* *}$ \\ work $(\mathrm{U})^{* *}$ \\ He needs a new pair of laces for his \\ starn (NONWORD)
}

*Acceptable completions. $\quad$ **Anomalous completions.

formed best completions (BC), such as the word "hammer" for the above context. (All of the sentence frames used had a single, generally agreed upon, best completion.) All three hypotheses predict facilitation for this set. A second set of stimuli contained words highly related to the best completions, as determined by a relatedness rating scale. "Wrench" would be a related (R) word for the above context. Some of these R words formed acceptable completions; others did not (see Table 1). The general facilitation hypothesis predicts facilitation for the $\mathrm{R}$ set, whether or not the target word forms a reasonable completion of the sentence frame. The acceptable completion hypothesis predicts facilitation for those members of this set that form acceptable completions. The specific facilitation hypothesis predicts no facilitation for this set. The third set of stimuli contained words unrelated to the best completion. The word "book" would be an unrelated (U) word for the sample context. As in the R set, the words in the $U$ set varied in how well they completed the context (see Table 1). Both the limited facilitation and the general facilitation hypotheses predict no facilitation for the $U$ set. The acceptable completion hypothesis predicts facilitation for those members of this set that form acceptable completions.

An additional set of stimuli contained nonwords as the target string (see Table 1). The nonwords followed the orthographic patterns of English and were therefore pronounceable. This set was necessary for the experimental task, but it was not involved in any of the predictions that differentiate the three hypotheses.

A large set of potential stimuli was developed by the author and subjected to several norming procedures (described below) in order to obtain stimuli with all the necessary characteristics. The final set of stimuli consisted of 42 sentence frames, which each had one $B C$, one $R$, and one $U$ word. These stimuli are listed in Appendix A.

The subjects for the norming procedures and the experiment itself were Stanford University students, none of whom participated in more than one task. The potential BC words were checked by having 26 subjects complete the potential sentence frames with single words. For the 42 sentence frames, $78 \%$ of the completions were the appropriate $\mathrm{BC}$ words and only $.7 \%$ of the completions were the $\mathrm{R}$ or $\mathrm{U}$ words. The relatedness of the $B C$ and $R$ words and the lack of relatedness of the $B C$ and $U$ words were checked by having 22 subjects rate the relatedness of the word pairs on a 1-5 scale, on which 1 signified "not at all related," 3 signified "somewhat related," and 5 signified "very related." The mean relatedness ratings were $4.1(\mathrm{SD}=.54)$ for the $\mathrm{BC}-\mathrm{R}$ pairs and $1.9(\mathrm{SD}=.54)$ for the $\mathrm{BC}-\mathrm{U}$ pairs.

As previously discussed, the words in the $R$ and $U$ sets varied in how well they completed the sentence frames. Twenty-two subjects rated how well each word completed its sentence frame, using a 1-5 scale on which 1 signified the word "doesn't fit the sentence at all" and 5 signified the word "fits very well." These ratings showed that the $R$ and $U$ sets of words contained equally 
good sentence completions. The mean ratings were $2.5(\mathrm{SD}=$ 1.0) for the $R$ set and $2.6(S D=1.1)$ for the $U$ set. These two sets were also approximately equated for frequency. The antilogs of the means of the logs of the Kucera and Francis (1967) frequency counts were 42 for the $R$ words and 55 for the $U$ words.

These stimuli were used in a preliminary study (reported in full in Kleiman, 1977, Experiment 1) that showed a large facilitation effect for the BC set, but no other significant effects. In order to increase statistical power for the other comparisons of interest, a new set of 42 sentence frames, each with one best completion, replaced the $\mathrm{BC}$ set given in Appendix A. These replacement stimuli are listed in Appendix B. The sentence frames and target words for the $R$ and $U$ sets were the same as those used in the preliminary study. Therefore, in the experiment to be reported, the stimuli consisted of 42 sentence frames, each with one $R$ and one $U$ word (listed in Appendix A), 42 different sentence frames, each with one BC word (listed in Appendix B), and, in addition, 48 more sentence frames that were paired with nonword completions. These additional sentence frames were like the others in all apparent aspects, so subjects were unable to use characteristics of the sentence frame context to predict whether a word or nonword would appear.

\section{Procedure and Design}

The stimuli were presented in a tachistoscope with an effective viewing distance of $51 \mathrm{~cm}$. All stimuli were typed on white cards using IBM Orator type. In the trials without context, the subject saw a fixation point and pressed an onset button, and $600 \mathrm{msec}$ later the fixation point disappeared and a string of letters appeared. Subjects decided whether or not the string of letters formed a word, and they signaled their responses by pressing the appropriate response button. They were instructed to do so as rapidly as they could while maintaining accuracy. For the context trials, subjects pressed an onset button, and the sentence frame appeared in the top half of the viewing field. They read the context once at their own rate and then pressed the onset button again. The sentence frame disappeared, and a fixation point appeared in the bottom half of the viewing field. After a $600-\mathrm{msec}$ delay, the fixation point disappeared and the string of letters appeared. Subjects then made their decision, as in the no-context trials. To insure that they were reading the context, after the response on randomly selected trials, subjects were asked to report the context.

Each of the 12 subjects participated in two sessions, about 1 week apart. This allowed a full set of data (one observation for each word in both the context and no-context conditions) to be collected from each subject without repeating any words or contexts in the same session. In each session, the subject received one block of trials in the context condition and one in the no-context condition. Half of the stimuli from each set appeared in each condition. Each block of trials was divided into three subblocks, each containing 21 word trials ( 7 of each stimulus set) and 16 nonword trials. The order of context and no-context blocks and the order of the subblocks were counterbalanced across subjects, as were the sessions in which each word appeared with and without context. The stimuli within each subblock appeared in a different random order for each subject.

\section{RESULTS}

The main findings were as follows: (1) A large facilitation effect was found for the BC set. This best completion effect was predicted by all three hypotheses. (2) Within the $R$ and $U$ sets, a facilitation effect was found for those words that formed reasonable completions for the sentence frames. This sentence acceptability effect was predicted by the acceptable completion hypothesis, but not by the others. (3) A facilitation effect was found for the $R$ set (relative to the $U$ set), independent of how well the word completed the sentence frame. This relatedness effect was predicted by the general facilitation hypothesis, but not by the others.

A preliminary analysis showed that reaction times were faster in the second session than in the first $\left[\mathrm{min} \mathrm{F}^{\prime}\right.$ $(1,25)=13.56, p<.01]$. However, this effect did not interact with any others, so the data from both sessions were combined for the following analyses. The error data did not show any significant differences, so only the reaction time data will be discussed.

Context differentially affected the three word types: The context by Stimulus Set interaction was significant $\left[\min F^{\prime}(2,86)=54.69, \mathrm{p}<.01\right]$. The differences among the stimulus sets in the no-context condition were not significant $\left[\min F^{\prime}(2,119)=1.43\right.$ ], with mean reaction times of 539,525 , and $521 \mathrm{msec}$ for the words in the $\mathrm{BC}, \mathrm{R}$, and $\mathrm{U}$ sets, respectively. ${ }^{2}$ The differences in the context condition were significant $\left[\min \mathrm{F}^{\prime}(2,88)=\right.$ $58.88, \mathrm{p}<.01]$. The mean reaction times and proportion of errors for each stimulus set in the context condition are shown in Table 2. As expected in this condition, mean reaction time for the $\mathrm{BC}$ set was significantly less than for the other two sets $\left[\min F^{\prime}(1,88)=113.34\right.$, $\mathrm{p}<.01]$. In addition, mean reaction time for the $R$ set was less than for the $U$ set $\left[\min F^{\prime}(1,84)=4.42\right.$, $\mathrm{p}<.05] .{ }^{3}$ Therefore, facilitation occurred for the words related to the expected words.

In order to test the acceptable completion hypothesis, an analysis taking into account how well each word completes the sentence frame was necessary. For this analysis, the $R$ and $U$ sets were each divided into three subsets according to the ratings of how well each word completed its sentence frame. The mean reaction times and error rates with context are shown in Table 3, divided into low, medium, and high sentence completion ratings (14 in each cell). The stimuli in the sentence

Table 2

Mean Reaction Times (RT) and Error Proportions (EP) in Context Condition

\begin{tabular}{cccccccc}
\hline \multicolumn{2}{c}{ BC } & & \multicolumn{2}{c}{$\mathrm{R}$} & & \multicolumn{2}{c}{} \\
\cline { 4 - 7 } \cline { 5 - 7 } RT & EP & & RT & EP & & RT & EP \\
\hline 444 & 0 & 533 & .02 & 555 & .04 \\
\hline
\end{tabular}

Table 3

Mean Reaction Times (RT) and Error Proportions (EP) for $\mathbf{R}$ and $U$ Words, Divided Into Low, Medium, and High Sentence Acceptability Ratings Sets

\begin{tabular}{ccccccccc}
\hline & \multicolumn{2}{c}{ Low } & & & \multicolumn{2}{c}{ Medium } & & \multicolumn{2}{c}{ High } \\
\cline { 2 - 3 } \cline { 8 - 9 } \cline { 7 - 8 } & RT & EP & & RT & EP & & RT & EP \\
\hline R & 555 & .04 & & 524 & .03 & & 520 & .01 \\
$\mathrm{U}$ & 582 & .08 & & 550 & .04 & & 542 & 02 \\
\hline
\end{tabular}


completion categories are marked $\mathrm{L}, \mathrm{M}$, and $\mathrm{H}$, respectively, in Appendix A. In the no-context condition, there were no differences among the reaction times for corresponding word sets $(F 1<1$ and $F 2<1)$. However, in the context condition data shown in Table 3, there was a significant sentence completion effect $\left[\min \mathrm{F}^{\prime}(2,60)=3.49, \mathrm{p}<.05\right]$.

The sentence completion effect did not interact with the relatedness effect: The Stimulus Type by Sentence Completion interaction was not significant $(\mathrm{F} 1<1$ and F $2<1$ ). Inspection of Table 3 shows that the $R-U$ difference was of the same magnitude in all three sentence completion categories. That is, there was facilitation of the $\mathrm{R}$ set even when the words did not complete the sentence in a reasonable way.

\section{DISCUSSION}

The experiment reported yielded three main findings about the effect of sentence frame contexts on lexical decisions: (1) Decisions for best completions (BC set) were much faster than for words from other sets. (2) Among words not generated as completions, decisions were faster for words related to the best completions (R set) than for words unrelated to the best completions (U set). (3) Also among words not generated as possible completions, decisions were faster for words that formed acceptable completions of the sentence frame than for words that did not. These relatedness and sentence acceptability effects were found to be additive: The sentence completion effect occurred in both the $\mathrm{R}$ and $\mathrm{U}$ sets, and the $\mathrm{R}-\mathrm{U}$ difference was the same when the target word was acceptable as a completion of the sentence as when it was not. The best completion and acceptable completion effects are consistent with context condition data reported by Fischler and Bloom (1979) and by Schuberth and Eimas (1977). No data relevant to the relatedness effect are provided by these studies.

The spreading activation, logogen, and verification models all offer accounts of the effects of single-word contexts. However, as they stand, they do not offer adequate accounts of the effects of sentence frame contexts, since they do not include the sentence comprehension processes and use of world knowledge necessary to determine best completions and acceptable completions. On the other hand, a schema-based model, such as that from which the sentence acceptability hypothesis was derived, can account for the best completion and sentence acceptability effects, but it does not provide any account of the relatedness effect or of the singleword context results.

In order to account for the entire set of results, a model must combine aspects of models of single-word context effects with processes of sentence comprehension and the use of world knowledge. A speculative combination model, which uses the construct of schemata in conjunction with a semantic network and the principles of spreading activation, is outlined below. The account of single-word context effects would be identical to that offered by the spreading activation model already discussed. That is, single-word contexts do not result in the use of schemata, since there is not sufficient information to enable the retrieval of appropriate schemata or the filling of any slots. A sentence frame context, however, does provide sufficient information to result in the retrieval of appropriate schemata and to fill some, but not all, of the slots. For one or more of the slots that are not filled, the default value and the constraints operate upon the semantic network to activate particular nodes. The default value activates the node representing it in the semantic network. For example, if the context is "He threw a rock at the house and broke a _._...," the default value most commonly accessed would be "window." Since the node representing the default value is directly activated, the word "window" will show a large facilitation effect. Activation will then spread from this node to related concepts, thereby producing facilitation for highly related words (e.g., door), whether or not they form acceptable completions.

The operation of the constraints upon the semantic network causes the sentence acceptability effect. These constraints are themselves concepts and, therefore, will be represented by nodes in the semantic network. For example, the constraints resulting from the context given above would specify that an acceptable completion must be part of or found at a house, must be a physical object, and must be breakable. According to the model, the schema acts upon the semantic network to activate the nodes representing the constraints, and this activation then spreads from these nodes. Any word that forms an acceptable completion must represent a concept that meets the constraints. It is assumed that concepts meeting the constraints are linked to the nodes representing the constraints. Therefore, activation will spread from each constraint node to those nodes representing acceptable completions, thereby facilitating recognition. That is, acceptable completions for the above example (e.g., dish, door, etc.) will have the properties of being physical objects, breakable, and found at houses, and therefore nodes representing these acceptable completions will be linked to the nodes representing these constraints. Since the acceptable completion nodes are not directly activated, the amount of facilitation will be smaller than for the best completions, which are directly activated. In addition, since the relatedness and sentence acceptability effects are determined by different initial activations, they would be predicted to be independent effects, as was found in this experiment.

A combination model of this sort is consistent with several previous proposals. Ortony (1978) has found 
a model combining schemata and semantic networks useful in accounting for results other than those considered here. Anderson's ACT model (Anderson, 1976; Anderson, Kline, \& Lewis, 1977) combines a network representation in which spreading activation occurs with a production system. The production system consists of rules that operate when specified conditions occur in the activated nodes of the network. Within the ACT model, schematic knowledge could be represented as production rules. Anderson suggests that the combination of these two types of processing enables an efficient system, since spreading activation determines a limited portion of the network, against which the conditions of the production rules are matched. Collins and Quillian (1972) also present a model of language comprehension that, in addition to a semantic network and spreading activation, includes procedures that operate upon the activated nodes in the network. The value of combination models such as these is well stated by Winograd $(1977$, p. 60): "Semantic networks are the only representation I have described which concentrates on the problem of retrieval-how to find the set of facts relevant to a given problem. The others have concentrated more on how to apply the facts when they are found. The two ideas might well be combined, since the strength of network systems is more in finding connections than in making use of them." The data reported here lend empirical support to the need for such a combination.

\section{REFERENCE NOTES}

1. Meyer, D. E., Schvaneveldt, R. W., \& Ruddy, M. G. Activation of lexical memory. Paper presented at the meeting of the Psychonomic Society, St. Louis, November 1972.

2. Kleiman, G. M. The scope of facilitation of word recognition from single word and sentence frame contexts (Tech. Rep. 133). Urbana: University of Illinois, Center for the Study of Reading, July 1979.

\section{REFERENCES}

Anderson, J. R. Language, memory and thought. Hilisdale, N.J: Erlbaum, 1976.

Anderson, J. R., KLine, P.. \& Lewis, C. A production system model of language processing. In M. A. Just \& P. A. Carpenter (Eds.), Cognitive processes in comprehension. Hillsdale, N.J: Erlbaum, 1977.

Antos, S. J. Processing facilitation in a lexical decision task. Journal of Experimental Psychology: Human Perception and Performance, in press.

BECkER, G. A. Allocation of attention during visual word recognition. Journal of Experimental Psychology: Human Perception and Performance, 1976, 2, 556-566.

Becker, C. A., \& Killion, T. H. Interaction of visual and cognitive effects in word recognition. Journal of Experimental Psychology: Human Perception and Performance, 1977, 3, 389.401.

Collins, A. M., \& Loftus, E. F. A spreading activation theory of semantic processing. Psychological Review, 1975, 82, 407-428.

Collins, A. M., \& Quillian, M. R. How to make a language user. In E. Tulving \& W. Donaldson (Eds.), Organization of memory. New York: Academic Press, 1972.

Fischle R, I. Semantic facilitation without association in a lexical decision task. Memory \& Cognition, 1977, 5, 335-339.
Fischle R, I., \& Bloom, D. A. Automatic and attentional processes in the effects of sentence contexts on word recognition. Journal of Verbal Learning and Verbal Behavior, 1979, 18, 1-20.

Fischle R, I., \& Goodman, G. O. Latency of associative activation in memory. Journal of Experimental Psychology: Human Perception and Performance, 1978, 40, 455-470.

JAMEs, C. T. The role of semantic information in lexical decisions. Journal of Experimental Psychology: Human Perception and Performance, 1975, 1, 130-136.

KLEIMAN, G. M. The effect of previous context on reading individual words (Tech. Rep. 20). Urbana: University of Illinois, Center for the Study of Reading, February 1977. (ERIC Document Reproduction Service No. ED 134 941)

Kucera, H., \& Francis, W. H. Computational analysis of presentday American English. Providence, R.I: Brown University Press, 1967.

Meyer, D. E., \& Schvaneveldt, R. W. Facilitation in recognizing pairs of words: Evidence of a dependence between retrieval operations. Journal of Experimental Psychology, 1971, 90, 227-234.

Meyer, D. E., Schyaneveldt, R. W., \& Ruddy, M. G. Loci of contextual effects on visual word-recognition. In P. Rabbitt (Ed.), Attention and performance $V$. New York: Academic Press, 1974.

Monton, J. The effects of context on the visual duration threshold for words. British Journal of Psychology, 1964, 55, 165-180.

MorToN, J. Interaction of information in word recognition. Psychological Review, 1969, 76, 165-178.

NEELY, J. H. Semantic priming and retrieval from lexical memory: Roles of inhibitionless spreading activation and limited capacity attention. Journal of Experimental Psychology: General, 1977, 106, 226-254.

OrTony, A. Remembering, understanding and representation. Cognitive Science, 1978, 2, 53-69.

Pillsbury, W. B. The reading of words: A study in apperception. American Journal of Psychology, 1897, 4, 315-393.

Posner, M. I., \& SNyder, C. R. R. Attention and cognitive control. In R. L. Solso (Ed.), Information processing and cognition: The Loyola symposium. Hillsdale, N.J: Erlbaum, 1975. (a)

Posner, M. I., \& SNyder, C. R. R. Facilitation and inhibition in the processing of signals. In P. M. A. Rabbitt \& S. Dornic (Eds.), Attention and performance $V$. New York: Academic Press, 1975. (b)

Rumelhart, D. E. Understanding and summarizing brief stories. In D. LaBerge \& J. Samuels (Eds.), Basic Processes in reading. Hillsdale, N.J: Erlbaum, 1977.

RUmelhart, D. E. Schemata: The building blocks of cognition. In R. J. Spiro, B. C. Bruce, \& W. F. Brewer (Eds.), Theoretical issues in reading comprehension. Hillsdale, N.J: Erlbaum, in press.

Rumelhart, D. E., \& Ortony, A. The representation of knowledge in memory. In R. C. Anderson, R. J. Spiro, \& W. E. Montague (Eds.), Schooling and the acquisition of knowledge. Hillsdale, N.J: Erlbaum, 1977.

Schuberth, R. E., \& Eimas, P. D. Effects of context on the classification of words and nonwords. Journal of Experimental Psychology: Human Perception and Performance, 1977, 3, 27-36.

Schvaneveldt, R. W., \& Meyer, D. E. Retrieval and comparison processes in semantic memory. In S. Kornblum (Ed.), Attention and performance IV. New York: Academic Press, 1973.

Shulman, H. G., \& Davison, T. C. B. Control properties of semantic coding in a lexical decision task. Journal of Verbal Learning and Verbal Behavior, 1977, 16, 91-98.

Stanovich, K. E., \& WEst, R. F. Mechanisms of sentence context effects in reading: Automatic activation and conscious attention. Memory \& Cognition, 1979, 7, 77-85.

Tulving, E., \& Golb, C. Stimulus information and contextual information as determinants of tachistoscopic recognition of words. Journal of Experimental Psychology, 1963, 66, 319-327. 
Winograd, T. Five lectures on artificial intelligence. In A. Zampoli (Ed.), Linguistic structures processing. Amsterdam: North Holland, 1977.

\section{NOTES}

1. This description of schemata neglects complications not critical to this discussion, such as how the filling of some slots can influence the constraints on others and whether the default values are retrieved or inferred.

2. All means presented in the text and tables are the means of the subject means. Reaction times from error trials and times more than 3 standard deviations from the subject's mean for a given condition were excluded from the data analysis.

3. A difference between the $R$ and $U$ sets of comparable magnitude was found in an earlier study (Kleiman, 1977, Experiment 1), although it was not statistically significant.

Appendix A

Sentence Frames, BC, R, and U Words

\begin{tabular}{|c|c|c|c|}
\hline Sentence Frame & BC Word & R Word & U Word \\
\hline 1. All the clothes the mourners wore were & black & M white & M dirty \\
\hline 2. Fluttering by was a pretty & butterfly & $\mathbf{H}$ insect & H leaf \\
\hline 3. The barbells the strong man lifted were very & heavy & H light & $\mathrm{H}$ old \\
\hline 4. The basketball players were all very & tall & H short & H nervous \\
\hline 5. The man who didn't eat all day was very & hungry & M thirsty & M lazy \\
\hline 6. The cup was placed on the & table & H chair & H floor \\
\hline 7. The parking lot was filled with & cars & H trucks & H trash \\
\hline 8. He threw a rock at the house and broke a & window & $\mathrm{M}$ door & M dish \\
\hline 9. No one at the zoo knew the name of the strange & animal & H dog & $\mathrm{H}$ visitor \\
\hline 10. The surprise party made him feel very & happy & H sad & $\mathrm{H}$ tired \\
\hline 11. In autumn he went looking for pretty colored & leaves & $\mathrm{H}$ trees & H clothes \\
\hline 12. It was a very dark & night & H day & H room \\
\hline 13. On a hot summer day many people go to the & beach & M sand & $\mathrm{H}$ theater \\
\hline 14. The magician took out his hat and made a rabbit & appear & L see & L laugh \\
\hline 15. The mother fed the newborn & baby & $\mathrm{L}$ diapers & L radio \\
\hline 16. The tired mother gave the dirty child a & bath & $\mathrm{H}$ towel & H cookie \\
\hline 17. On top of the hamburger there was melted & cheese & L mouse & L plastic \\
\hline 18. He bought a wall-to-wall & carpet & M drape & H poster \\
\hline 19. The trained seal performed a clever & trick & $\mathrm{M}$ joke & M song \\
\hline 20. They baked many loaves of & bread & L cake & L clay \\
\hline 21. He put a clean sheet on the & bed & M pillow & $\mathrm{M}$ ground \\
\hline 22. The king of beasts is the & lion & $\mathrm{L}$ roar & L work \\
\hline 23. The sick man had only six months to & live & M breathe & M pay \\
\hline 24. He always forgets because he has a poor & memory & L think & L speech \\
\hline 25. The hikers slowly climbed up the & mountain & $\mathrm{H}$ valley & M stairs \\
\hline 26. The sad ending made many people & cry & $M$ tears & H leave \\
\hline 27. Eat right for good & health & M medicine & L money \\
\hline 28. The child was frightened, but it was just a bad & dream & H night & M picture \\
\hline 29. She sewed the button on with some thread and a & needle & L sharp & L heavy \\
\hline 30. The Atlantic is a vast & ocean & M water & M plain \\
\hline 31. He has trouble adding and subtracting large & numbers & L letters & L weeks \\
\hline 32. In the crowd there were all kinds of & people & L places & L tools \\
\hline 33. While skiing he broke his & leg & M shoe & L hat \\
\hline 34. The old horse moved very & slowly & H fast & M often \\
\hline 35. Almost everyone has ten & fingers & $M$ gloves & $\mathrm{H}$ pencils \\
\hline 36. There are two pints in a & quart & L milk & $L$ recipe \\
\hline 37. The orchestra played very pretty & music & L noise & L shells \\
\hline 38. He sanded the wood until it was & smooth & L hard & M broken \\
\hline 39. While the national an them plays, everyone is expected to & stand & L sit & L turn \\
\hline 40. He hit the nail with a & hammer & H wrench & M book \\
\hline 41. Last night there was a full & moon & M sky & M party \\
\hline 42. He was stung by a & bee & L flower & $\mathrm{M}$ fish \\
\hline
\end{tabular}

Note-The BC words listed here were used to determine the $R$ and $U$ words. The BC stimuli actually used are listed in Appendix $B$. $H=$ high sentence acceptability set; $M=$ medium sentence acceptability set; $L=l o w$ sentence acceptability set. 
Appendix B

BC Set Sentence Frames and Words

1. He was so frightened he was white as a

2. Three heavy bags is more than he can

3. More money buys fewer products during times of

4. Three people were killed in a terrible highway

5. The defendant is charged with

6 . The heavy rains caused a massive

7. The baby weighed six pounds at

8. I can't write on the blackboard without any

9. For breakfast she wanted bacon and

10. At noon they took a break for

11. Lincoln was born in a $\log$

12. The children enjoyed the three ring

13. He campaigned so he would win the

14. He can't hear you because he is

15. December is the last month of the

16. The prisoners were planning how they would

17. To keep animals out of the garden, he put up a

18. He forgot to buy something, so he went back to the

19. The politician spoke out for law and

20. A red light is a signal to

21. The new store had a grand

22. To help wake up, he needed a cup of

23. After being robbed, he called the

24. It's unlucky to walk under a

25. The lecture should last about one

26. The careless smoker caused a forest

27. He had to wake up early to get there on

28. He was lucky enough to win first

29. The prison sentence was only six

30. There have been two world

31. Some say a dog is man's best

32. It felt much colder when the sun was behind a

33. Because he had a toothache, he called the

34. The old man has a long gray

35. After a long wait, the package finally

36. The wet clothes were hung outside to

37. The underpaid workers went on

38. When he was 65 , he had to

39. Hawaii is the newest

40. He died of a heart

41. The over-weight man went on a

42. The minister pronounced them man and

ghost

carry

inflation

accident

murder

flood

birth

chalk

eggs

lunch

cabin

circus

election

deaf

year

escape

fence

store

order

stop

opening

coffee

police

ladder

hour

fire

time

prize

months

wars

friend

cloud

dentist

beard

arrived

dry

strike

retire

state

attack

diet

wife

(Received for publication May 29, 1979;

revision accepted February 8,1980 .) 